\title{
Uma experiência blog no mercado-mídia contemporâneo
}

\section{A blog experience in the contemporary market-medias}

\author{
Wilton Garcia \\ Fatec Itaquá / Uniso \\ Doutor em Comunicação pela USP. Professor da Fatec Itaquá/SP e do Mestrado em Comunicação \\ e Cultura da Uniso \\ wgarcia@usp.br
}

Resumo: Este artigo aborda uma reflexão acerca de estratégias que perpassam blog e mercado-mídia, em especial quando permeia o consumo. $\mathrm{Na}$ medida do possível, esboçam-se aspectos intersubjetivos sobre o campo contemporâneo da Comunicação, cada vez mais fragmentado e não linear. O blog http://grandtextauto. org ilustra a web 2.0. E o eixo teórico baseia-se nos estudos contemporâneos, os quais relacionam e aproximam os estudos culturais e as tecnologias emergentes. Como resultado, este debate enfatiza temas teóricos, socioculturais e políticos da sociedade, em busca de atualização e/ou inovação de tensões sociais, fenômenos e valores humanos. Palavras-chave: Blog, mercado-mídia, Estudos Contemporâneos.

Abstract: This article addresses a thinking about strategies that underlie blog and market-media, especially when it permeates consumption. As far as possible, outline is intersubjective aspects of the contemporary field of communication, increasingly fragmented and not linear. The blog http://grandtextauto.org shows the web 2.0. And the theoretical development is based on contemporary studies, which relate to and approach cultural studies and emerging technologies. As result, this discussion emphasizes theoretical, sociocultural and political issues of society in search of update and/or innovation of social tensions, phenomena and human values.

Keywords: Blog. Market-media. Contemporary studies. 


\section{Introdução}

Atualmente, a experiência do consumo mostra-se como situação recorrente e, talvez, pareça ser sem muito critério de avaliação por parte do consumidor na dinâmica do mercado em consonância com a mídia; embora o consumidor esteja bastante atento. Isso legitima a voz hegemônica do inseparável binômio mercado-mídia na expectativa de "vender" mais mercadorias e alcançar a meta do mundo capital, que pressupóe a lucratividade por demanda: ganhar cada vez mais, em abundância.

Por conseguinte, percebe-se que ambos, mercado-mídia, estão tão imbricados e seria impossível estudar um sem o outro. E a sociedade tem testemunhado um crescente número de instrumentos persuasivos para promover a divulgação de marcas, produtos e/ou serviços no mercado-mídia com um ideal discursivo (de publicidade, propaganda e marketing) direcionado ao consumo. Este último, em larga escala - massificada e industrial -, acontece de forma intensa e constante.

Para Deleuze e Guattari (1997, p. 131) “a troca é sempre uma aparência”. A troca elenca a fragilidade do sujeito em uma instância superficial e demonstra características como carência e insegurança (EAGLETON, 2005). Essa fragilidade surge na ação humana contemporânea, (re)dimensionada pela sagacidade mercantil-midiática. O entusiasmo de uma pseudossociabilidade do sujeito, com frágeis relacionamentos virtuais, explora linguagens, veículos e práticas específicos da comunicação tecnológica superficial nas redes (KEEN, 2012; CASTELLS, 2000).

Disso urge uma reflexáo acerca de estratégias que perpassam o consumo apontado pela blogosfera, cujo eixo teórico se baseia nos estudos contemporâneos. Tais estudos relacionam e aproximam os estudos culturais (BHABHA, 1998; EAGLETON, 2005; HALL, 2005) e as tecnologias emergentes (CASTELLS, 2000; KEEN, 2012; LEMOS, 2013; PRIMO, 2008; RECUERO, 2009).

$\mathrm{Na}$ expectativa de experimentar os pressupostos reflexivos propostos neste trabalho, o endereço eletrônico <http://grandtextauto.org> foi eleito como objeto de exemplificação. Produzido de forma colaborativa, o blog compreende a participação coletiva do usuário-interator, com textos - muito mais que comentários - para a produção editorial de uma publicação, em formato livro (digital e impresso).

Nesse fluxo, pontua-se um expressivo leque de temas variáveis, como: hipertexto, interface, interatividade, redes sociais, simultaneidade, virtualidade etc. A produção de conhecimento de tais conceitos dinamiza uma extrema complexidade do pensamento humano ${ }^{1}$ na atualização de dados e referentes tecnológicos da cultura digital, tão presente e utilizada no cotidiano da sociedade hoje. Como pesquisador, procuro esboçar ideias (inquietudes, impressóes e/ou posicionamentos) que, de alguma 
maneira, tentam ajudar na reflexão a respeito dos efeitos tecnológicos. Do ponto de vista da área da Comunicação, o percurso metodológico aqui se organiza a partir de uma ênfase exploratória, empírica e qualitativa, cujo desenvolvimento de leitura do referido blog acontece em três etapas: observação, descrição e discussão.

Realizados tais indicativos preliminares, a presente escrita destaca três tópicos: da linguagem, da blogosfera e do exemplo. Dessa forma, organizam-se níveis distintos e, ao mesmo tempo, complementares que articulam características do contexto a ser explorado discursivamente.

\section{Da linguagem}

$\mathrm{O}$ (re)condicionamento de qualquer discursividade temática perpassa um espaço de fruição constante, na proposição da linguagem. Logo, percebe-se que instabilidades ilustram as expressóes e associam a condição contemporânea. Esta última torna-se capaz de prever a flexibilidade e o deslocamento como atividades inerentes à linguagem e suas caracterizaçôes atuais: não linear, fragmentada, descontínua, simultânea, heterogênea, sincrética, acelerada, aberta, hermética, paródica, incompleta e impactante. Hoje, as circunstâncias para (re)pensar as coisas no mundo ponderam um evento/acontecimento percebido pela apresentaçáo e pelo modo de estudar (observar, descrever e discutir) suas recorrências, mediante a crise da representação. Metaforicamente, os referentes estão em guerra. A linguagem instaura-se para sistematizar a expressão do discurso, em sua ambientação de processo mutável e deslizante.

Para Eagleton (2012, p. 111), "pensamos como pensamos, então, por causa do tipo de animais que somos. Se nosso pensamento se estende no tempo é porque nossos corpos e nossas percepçóes sensoriais também o fazem". Como suposição, tal regulação estabelece um agir massificado do Ser Humano, em que o sujeito fragilizado e inseguro passa a ter atitudes e vontades mais homogêneas, padronizadas, quiçá customizadas pelas propostas do chamado mercado-mídia. Esse posicionamento demonstra o enfraquecimento da individualidade do sujeito contemporâneo.

A ideia de contemporâneo, assim, tange à atualização da linguagem - estratificada por cultura e representação (ver figura 1). Ainda que constituam uma dimensão estrutural, ambas - cultura e representação - sintetizam, respectivamente, contexto e objeto como um quadro relacional, o qual fortalece e exprime predicaçóes da discursividade. Essa aproximação de cultura e representação organiza contexto e objeto, no fluxo dos estudos culturais. Nesse caso, ambos produzem um coeso território de situações flexíveis sobre o pensar: isto é, o saber predisposto ao fazer e vice-versa.

De um lado, a cultura está atrelada à experiência humana (o sentir), 
ao acompanhar e acomodar diversos fatores que concernem às estratégias discursivas. Mais que hábitos e costumes, são situaçôes inerentes ao uso peculiar da discursividade no cotidiano. A cultura relaciona o viver, bem como a experimentaçáo tecnológica, seja do digital ou do consumo. Trata-se de uma dinâmica que ressignifica a natureza a cada manhã, a cada clique. Segundo Canclini (2008, p. 28): "Em algumas formas de expansão do consumo, como Internet [...] criam-se melhores condiçóes para que nós, consumidores, sejamos capazes de apreciar repertórios culturais e estéticos diversos".

De outro, a representação estimula uma saída contundente pela subjetividade: espaço de (im)possibilidades simultâneas, espaço de imaginação e criação: um tom inventivo. Com as tecnologias emergentes, tentar representar um objeto requer ativar a atualização da cena performatizada. Tem a ver com uma apresentaçáo que se reitera. Isso permite observar as coisas que surgem nas ideias, como: referências, signos, representaçôes, lembranças ou memórias que acusam presença (GUMBRECHT, 2010).

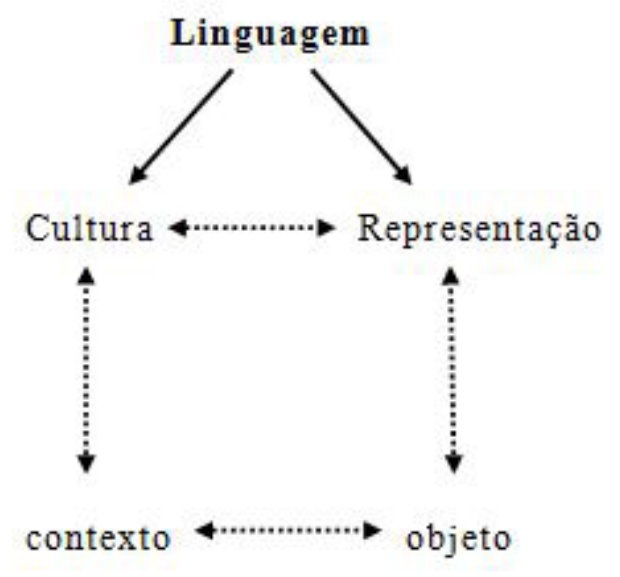

Figura 1: esquema ilustrativo

$\mathrm{Na}$ medida em que ocorre o percurso entre contexto e objeto (e vice-versa), perfaz-se o discurso capturado em sua intensidade descritiva, o que provoca a exaustáo de um observar (o olhar). Isso se acopla ao interesse pelas novidades tecnológicas, por exemplo. Sabe-se que um discurso não exprime, necessariamente, uma ação, mas pode intensificar um comportamento ou uma atitude observadora de contexto e objeto. Assim, um limite de fronteiras permeia intervalos da dúvida e do conhecimento - um efeito metonímico; de aproximaçáo do contexto e objeto. Das possibilidades de representar qualquer contexto e objeto, urgem condiçóes adaptativas recorrentes da cultura digital, como estado híbrido e provisório. O efeito metonímico compara o contexto e objeto no enlace (relacional) direto de conter e estar contido, que dinamiza a pertença.

Já para Pais (1993), há um modo de gerar uma posição mediante a 
adaptabilidade discursiva do consumo, conforme figura 2:

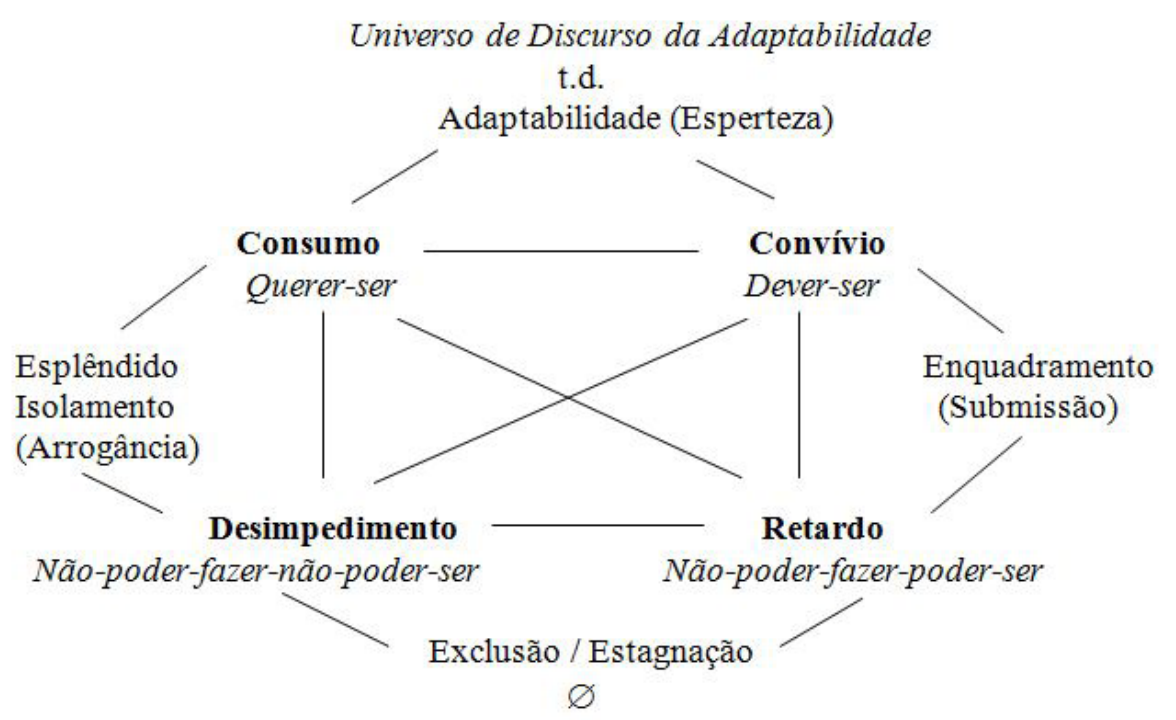

Figura 2: U. D. da Adaptabilidade (PAIS, 1993, p. 334)

Essa figura esquemática demonstra a articulação do discurso sobre o consumo em meio à adaptabilidade no processo de convívio, desempenho e retardo da informação. Os enunciados dessa adaptabilidade (re) forçam o consumo como resultado. Tal perspectiva organiza um eixo sistêmico de representaçôes semióticas, cujas varáveis enunciativas ponderam a lógica formal de resultado mercadológico-midiático.

Do ponto de vista tecnológico, a linguagem ultrapassa os eixos da comunicação e da cultura no mercado-mídia para abarcar outras instâncias discursivas capazes de alterar a compreensão das mensagens reguladoras. Isso pode ser perigoso, uma vez que não há critério muito claro senão o da manipulação de mensagens mercadológico-midiáticas - como informações e, dessa forma, usos indevidos de determinadas tecnologias que fragilmente se quebram, para novos produtos serem adquiridos. Em outras palavras, divulga-se e vende-se um produto para ser consumido e não utilizado, longe de ser durável. Como resultado parcial da Revolução Industrial que ecoa na contemporaneidade, seria a máxima escritura pulsional do descartável em pauta. Portanto, pode-se considerar que esse acordo deslizante dos enunciados contemporâneos produz um movimento fértil, simultâneo de deslocamento e flexibilidade.

Estratégias discursivas intertextuais equacionam os códigos visual, sonoro, textual e/ou sincrético da linguagem - estratificada por cultura e representação, conforme já exposto neste trabalho. Isso quer dizer, sintetizam contexto e objeto, respectivamente, como dado relacional, o qual fortalece e exprime predicaçóes discursivas da cultura digital (MACIEL, GONZALES, REBECHI JR., 2014), incluindo as nuances da blogosfera. 


\section{Da blogosfera}

A cultura digital compreende fatores técnicos, estéticos e éticos, ao dissipar significativas transformações na sociedade contemporânea. As tecnologias emergentes promovem essas mudanças metamorfoseando proposiçóes computacionais, que se estabelecem diferenciadas. Hoje, falar em mudança implica observar os avanços digitais que surgem com as tecnologias emergentes, o que amplia o ambiente comunicacional e suas estratégias discursas. Assim, o digital expõe "novas/outras" práticas de uso e função de tais dispositivos (DELEUZE, GUATTARI, 1997).

No mercado de informação, a blogosfera surge como referência discursiva impactante, em que os códigos (texto, imagem e som) tomam formas autônomas do pensamento, em uma estratificação de ideias. Dito de outra forma, o blog surge como registro sequenciado de comentários e opinióes que se acumulam em um endereço eletrônico, com a facilidade dos suportes computacionais disponíveis na internet. Trata-se de uma manifestação que reúne, em qualquer blog, um conjunto de informaçóes e (des)dobra o tecimento de ideias e seus hipertextos.

No fluxo da informação surge o blog: soma dos termos "internet" e "lugar", abreviatura da palavra weblog (SPYER, 2009, p. 53), que significa um local discursivo na rede mundial de computadores. Habitualmente, foi traduzido como "diário da rede" (web + log), por analogia ao "diário de bordo" (ship log). Atual fenômeno digital, o blog apresenta-se para além de mero diário (PRIMO, 2008) de anotaçóes ou memórias documentadas na internet, cuja interatividade com leitores (usuário-interator) ocorre a partir da inserção de comentários sobre os posts publicados.

Um blog pode ser, entáo, um website de discussão com ferramentas simples de publicação, em uma escritura individual ou coletiva, conforme a dinâmica estabelecida pelo usuário-interator, que realiza a abertura inicial do endereço eletrônico. A simplicidade na produção do blog otimiza a transferência de dados. Isso simplifica as manifestaçóes na internet sem reduzir a qualidade da informação. Essa simplicidade quer dizer síntese e dinâmica, isto é, ser objetivo no uso de instrumentos e conteúdos pode potencializar a produção de mais informaçóes com mais eficiência e clareza. Todavia, isso garante a maximização de uma publicação recorrente e constante.

O neologismo "blogar", na língua portuguesa, inaugura uma forma autônoma de pensamento a respeito da informação tecnológica e pressupôe uma noção de blog, em que texto, imagem e som agenciam/negociam sua expressão on-line.

Na lógica mercantil-midiática, esse tipo de informação tecnológica instaura-se em um percurso reflexivo acerca do escopo (capital) do consumo. Seria, então, relevante considerar que as mediaçôes tecnológicas 
alavancam a sociedade atual, em particular na dinâmica da blogosfera. A identificar o consumo nas experiências cotidianas, ocorrem atualizaçôes em circunstâncias divergentes que fazem a sociedade, hoje, (re)pensar a respeito dos parâmetros comunicacionais nas relaçóes sociais.

Segundo Canclini (2008), o blog convoca um modo de agir na sociedade. De fato, a qualidade do conteúdo de um blog equivale aos parâmetros necessários para prever o grau de influência que coordena a incursão digital da informação divulgada. Seria um jeito mais democrático de diálogo e consumo.

Desde 2004, os relatórios produzidos pelo site Technorati <http:// technorati.com> indicam que o "estado da blogosfera" tem-se ampliado de modo vertiginoso. E, ao averiguar o que está em voga na internet - por exemplo, as redes sociais -, estabelece-se uma imediata mediação de fatos e notícias (jornalísticas, publicitárias etc.), como assunto discutido em um diário digital (FERRARI, 2010) de imprensa. Isso legitima um blog a partir de sua periodicidade, bem como da qualidade da informação.

Nesse sentido, investe-se especificamente na percepção aguçada dos blogueiros que questionam os parâmetros reguladores e, ao mesmo tempo, emblemáticos do consumo. Dito de outro modo, a disponibilidade de um blogueiro para escrever sobre o mercado-mídia coloca-o em uma situação confortável para opinar e/ou sugerir. A (dis)junção de um suposto valor de "verdade" no ambiente digital entoa um grau verossímil, uma vez que a influência de opinióes e posicionamentos efetiva-se em estímulos (comportamentais, ideológicos, entre outros).

Hoje, a partir da internet, o sujeito passa a ser considerado usuário-interator, cuja situação parcela, compartilha, coopera, conecta. Essa experimentação interpela, interfere e se confirma por meio de um diagrama transversal que utiliza um amplo discriminar de características complementares. Determinadas performances (atitudes e/ou comportamentos) on-line de blogueiros são seguidas e sequenciadas, de acordo com a sugestão de leituras que expóem, discute e provocam a condição representacional do sujeito - em um avatar ${ }^{2}$, por exemplo - na rede mundial de computadores.

Da perspectiva hipermidiática, são estados de intersubjetividade, porque envolvem o sujeito e sua sujeição intersubjetiva (BHABHA, 1998). Mais que isso, imprime urgência nas mudanças de valores e novidades no cotidiano. Para Curtain (2004), é difícil recapitular o impacto de uma história curta no blog (como anedota para a exemplificação), embora se verifique a qualidade de sua documentação. A criação de um blog, na internet, possibilita a documentação e o registro das atividades desenvolvidas no cotidiano. Inevitavelmente, isso vivifica um corpus empírico de possibilidades alternativas digitais sobre o campo contemporâneo da 
Comunicação atrelado ao consumo, no mercado-mídia. Os diversos tipos de registro em blogs equacionam depoimentos, entrevistas, dicas e/ou sugestôes, entre outros. Constatam-se técnicas discursivas apropriadas que abordam, de alguma maneira, as diferentes propriedades discursivas.

Para Primo (2010, p. 7), "apesar de não ter fins mercadológicos, um blog pessoal pode também construir uma reputação de excelência”. E sinalizado no panorama digital a partir da blogosfera, o consumo transversaliza "novos/outros" parâmetros comunicacionais. São diferentes - e às vezes divergentes - possibilidades de blogs, que servem como conjunto de informação sobre características específicas que enunciam traços da dinâmica comunicacional.

$\mathrm{Na}$ economia do saber, seria a articulação discursiva de algo inusitado a ser adquirido, a partir da blogosfera, como premissa de um mero modismo consumista. Do ponto de vista informacional, a produção de conteúdo no blog relaciona a condição adaptativa de pensar entretenimento, lazer, informação, serviço e/ou opinião. O processo comunicacional, via blog, acena para determinadas tendências comerciais e empresariais que (de)marcam algumas variáveis discursivas. Essas variáveis potencializam o blog, o qual pode promover o status atrativo para o mercado-mídia. Isso gera embates, tendências e preferências em torno dos interesses dos negócios.

De acordo com Canclini (2008, p. 88-89):

\begin{abstract}
Num tempo em que o poder se concentra em megaempresas, as comunidades virtuais alternativas poucas vezes conseguem tirar o mistério dessas sociedades anônimas. Não faltam blogs e fóruns que enxertem, nos mais de cem milhóes de sites da web, e façam chegar a alguns dos mais de bilhóes de internautas, informaçáo sobre negócios que durante anos foram secretos. Mas também na Rede o poder está desigualmente distribuído e desregulado: poucos são os que têm o privilégio de conhecer as compras que você fez, suas viagens, os países que você visitou, suas crenças religiosas e a de todos os demais, os que podem pagar agências de propaganda para que simulem blogs e fóruns de consumidores, pesquisas de opiniāo sobre os paradigmas da moda e sobre as preferências políticas.
\end{abstract}

Depositário de ideias, o blog funciona como fluxo contínuo de anotaçôes que percorrem as malhas discursivas do tecido tecnológico e revoluciona a comunicaçáo computadorizada em rede, mediante determinada produção de conteúdo. Ao escrever sobre as redes sociais, Keen (2012, p. 176-177) afirma que "o mercado, claro, é simplesmente um reflexo de nossos desejos e açóes coletivos. E é de se esperar que nós, como o mercado, rejeitemos muito das redes sociais mais absurdas ou destrutivas, agora fundadas na corrida do ouro social".

Açôes inclusivas na internet, indiscutivelmente, possibilitam um empenho comunicacional, de acordo com efetivas relaçôes humanas. 
Garantir a manutenção dessa comunicação faz parte de uma lógica contemporânea que comporta a ativa participação do sujeito, em sua cidadania plena - sem desigualdade social excludente que rechaça a população (BHABHA, 1998; CANCLINI, 2008; HALL, 2005; VILLAÇA, 2011). Por isso, democratizar o acesso via comunicação tecnológica pode ser uma solução governamental das políticas públicas, inclusive, pois a publicação de conteúdo na internet incentiva o usuário-interator a utilizar o espaço de comentários de um blog para conversar (dialogar, discutir, sugerir ou opinar) sobre o assunto em questão.

Dessa vertente, a intenção seria refletir sobre os modos de produção da informação e da comunicação que representam o consumo na blogosfera como adversidade junto às tecnologias emergentes. Seria, de fato, pensar uma condição humana de independência, da ideia à expressão - a expressão pública do sujeito. Verifica-se uma criteriosa passagem de etapas comunicacionais que intermediam instâncias de imaginação e imagem a se desdobrarem em manifestaçóes plausíveis. Disso, almeja-se a oportunidade do pensar para além do consumir.

Para Keen (2012, p. 166):

A tirania social que toma conta da liberdade individual na era hipervisível de hoje, por exemplo, era um problema conhecido na época da mecânica de massa. E também uma promessa utópica de que a tecnologia contemporânea pode superar as divisôes da humanidade e unificar todos nós numa aldeia global de compreensão e simpatia mútuas.

A blogosfera arma-se pela compreensão do objetivo proposto: tentar inovar a discursividade agenciada pelas estratégias que informam acerca de mercado-mídia, ao refletir a respeito do blog como dispositivo (DELEUZE, GUATTARI, 1997) de consumo. Portanto, verifica-se em qualquer blog um jogo de informaçóes que (des)dobra o tecer de ideias e respectivos referentes hipertextuais, os quais provocam (re)ações distintas.

\section{Do exemplo}

Parte da sociedade tecnológica questiona essa flexibilidade do sujeito, ainda mais ao relacionar a blogosfera no mercado-mídia contemporâneo, porque o blog também pode funcionar como canal de posicionamento e/ou denúncia, em determinada situação. Por isso, o endereço eletrônico <http://grandtextauto.org> serve para ilustrar a web 2.0 indubitavelmente.

De acordo com sua apresentação, este endereço eletrônico foi fundado em 2003. Trata de uma comunidade virtual Grand Text Auto (GtxA) temas variáveis como mediação por computador e trabalhos em 
diferentes formatos: ficção interativa, artenet, poesia eletrônica, drama interativo, ficção hipertextual, jogos de computador, ambientes virtuais compartilhados, entre outros. São discussões teóricas, metodológicas e/ ou conceituais sobre narrativa computacional, design, games, poesia e arte digital etc.

Atualmente, GTxA é um agregador para um grupo distribuído de vários outros blogs. Os autores desses demais blogs funcionam como teóricos e desenvolvedores e estão interessados nas discussóes que tematizam arte, design e tecnologia, bem como as questóes de interação e recepção na cultura digital. Também, nesse endereço eletrônico, há postagens de breves ensaios que circundam o debate crítico-conceitual sobre o universo tecnológico, por ora, pesquisado. Isso corresponde direto aos cliques de escolhas e decisôes do sujeito (usuário-interator), que mapeia o gosto, o desejo, a necessidade, a preferência e a decisão traduzidos em consumo tecnológico. Ou seja,

Por meio das escolhas/decisôes, são potencializados certos elementos sociotécnicos em detrimento de outros, da mídia digital, fenômeno que pode ser comprovado a partir da observação de marcas/traços relativos à organização das açóes empreendidas nos blogs corporativos presentes na blogosfera brasileira (LASTA; BARICHELLO, 2013, p. 250).

Aqui, o consumo aproxima-se da expectativa de apreender, reter a informação a partir de diferentes pontos de vista, inclusive posicionamentos divergentes. Todavia, torna-se relevante considerar que o consumo alavanca a sociedade contemporânea com suas mediaçóes tecnológicas, mediante as convergências (hiper)midiáticas (MACIEL, GONZALES, REBECHI JR., 2014), as quais compreendem excessos de determinadas atividades, bem como sua própria obsolescência. De forma indiscutível, o consumo ressalva-se como imagem a ser desgastada pelo usuário-interator (CANCLINI, 2008).

Segundo Manovich (2008), Noah Wardrip-Fruin, professor de comunicação da Universidade da Califórnia, em San Diego (Estados Unidos), propôs a seu editor na MIT Press - editora da Massachusetts Institute of Technology - a criação de um blog para deslanchar a revisão por pares (peer review), em uma ação colaborativa de leitura diária de sua escrita, na internet. Essa metadiscussão, que distribui e destrincha a informação por etapas, ocorreu na comunidade virtual GtxA. A comunidade GtxA, da qual Noah Wardrip-Fruin participa ativamente, representa uma rede intensa de estudiosos, pesquisadores, professores e especialistas de mídia, artistas, designers, gamers e profissionais de jogos, prontos para criticar tal trabalho interdisciplinar.

O percurso metodológico dessa investigação científica indica que nos dias úteis, ao longo de dez semanas, o autor divulgou, em formato 
post (postagem de textos), fragmentos de seu manuscrito, que aos poucos foi apresentado ao leitor (usuário-interator). A dinâmica era ler, comentar, criticar e/ou sugerir mudanças. Enfim, ficou estabelecida uma ação de pensamento compartilhado por múltiplos olhares, em que os envolvidos pudessem, na medida do possível, cooperar de modo interdisciplinar, com suas posiçóes e opinióes, sobre o ponto de vista do autor.

A expectativa de Wardrip-Fruin era receber retornos (feedbacks) de qualidade, uma vez que os possíveis participantes eram especialistas (acadêmicos e intelectuais) da cultura digital que pesquisam as tecnologias emergentes. E, paulatinamente, a proposta fragmentada ganhou corpo diante do envolvimento reflexivo e investigativo dos interessados. A colaboração foi fundamental para o desenvolvimento da proposta.

A efetivação do resultado, de fato, foi o livro Expressive processing (WARDRIP-FRUIN, 2009), que aborda um amplo universo contemporâneo de ficçôes digitais, jogos e estudos de software, entre outros assuntos similares. São questóes complexas, levantadas e aprofundadas pelo autor, mediante comentários dos usuários-interatores, que participaram direto dessa produção editorial. $\mathrm{O}$ volume de informaçóes do livro foi alterado, de acordo com as diferentes posiçóes e comentários, debatidos publicamente no endereço eletrônico.

De acordo com Consoni (2003, p. 138),

Os autores dos blogs são influenciados pela participação dos comentaristas nos espaços de comentários. A conversação entre comentarista e autor pode inclusive fazer com que a postagem seja modificada ou que novas postagens surjam a partir da interação mantida no ambiente. Mas não se trata apenas de uma sugestão de pauta, como é comum na imprensa institucionalizada. Os próprios autores desejam manter a bidirecionalidade da interação nos comentários para aprenderem com seus comentaristas, pois essa interação os transforma.

Nesse caso, a blogosfera serve para (re)colher distintos posicionamentos do usuário-interator, a serem reestabelecidos por atualizaçôes, conforme conveniência do proponente. O experimento descrito ajuda a legitmar a relevância do uso da ferramenta blog como espaço hipermidiático de agenciamento/negociação em comunidades virtuais. Como exercício compartilhado, deposita-se, expóe-se e (re)formula-se a complexidade de elementos e práticas que compreendem a informação.

Incontestavelmente, um blog pressupóe uma inciativa diferente - em sua razáo de existir - em que cada projeto acontece, de acordo com a informação que se complementa, com a reflexão de cada usuário-interator. E a elaboração de uma proposição criativa convida para a reflexão acerca da flexibilidade necessária às (re)formulaçôes híbridas das tecnologias emergentes, em especial os intercâmbios das informaçóes comunitárias na blogosfera. Esse ressignificar comunitário - na forma de 
utilização do blog - amplia a imagem e o escopo dos modos de produçáo do conhecimento e a consequente ideia de consumo no mercado-mídia.

Eis um paradoxo criado pela internet: o consumidor agora participa, efetivamente, do processo de elaboração do produto a ser comercializado. Do ponto de vista comunicacional, a atmosfera digital que enuncia cidadania e consumo parece ser enfática com seus paradoxos (CANCLINI, 2008), pois açôes e imagens (hiper)midiáticas fomentam o incessante faturamento comercial. Reforço que esse paradoxo exemplificado estabelece uma "nova/outra" lógica para o mercado-mídia a ser (re) dimensionada, em particular à cultura digital. Esta última contribui para tal situação, uma vez que enfatiza o ambiente comunicacional tecnológico. A rede mundial de computadores, a internet, acena para o fenômeno da blogosfera como lugar de debate e desafio sobre o mercado-mídia, em especial quando permeia a noção de consumo.

A versatilidade dos valores de uso e função de produtos, marcas e serviços (a valoração e a sujeição humana) digitais atrelam às artimanhas da cultura contemporânea e à emergência de um experimento diferenciado. Nesse sentido, vale uma revisão crítica, cujo veículo de ideia e pensamento é explorado de maneira adjacente ao desempenho coletivo em prol de determinada resultante não apenas do mercado-mídia, mas também em benefício da sociedade. Isso (re)configura as predicaçôes perenes em cada manifestação digital, sobretudo o escopo radical das representações contemporâneas.

Comparados o desempenho e o aperfeiçoamento da atividade coletiva proposta por Wardrip-Fruin (2009), a divulgação e o consumo no blog surpreendem pela ousadia de antecipar a exposição dos fragmentos textuais, mas também de arriscar a mostra parrcial de suas ideias. A inovação que (re)processa o sistema de revisão por pares da editora demonstra a iniciativa eloquente do autor para pensar, de modo diferente, sobre a condição de mercado-mídia.

Também, constata-se a necessidade de compreender a dinâmica laboratorial, que atualiza o fluxo percepto-cognitivo de operar diferentes possibilidades digitais como agenciamento/negociaçáo. Mais que isso, efetiva um resultado recorrente desse experimentar, cujo envolvimento do usuário-interator produz uma escritura pública, a qual se (re)faz diante de comentários, opinióes, críticas e, simultaneamente, o próprio consumo da informação. Experimentar, aqui, seria a palavra de ordem, em que as coisas no mundo e as novidades ressurgem com a artimanha interativa de envolver o sujeito.

Parece que o livro de Wardrip-Fruin descartou a novidade como estratégia de marketing do mercado-mídia e ressaltou um paradoxo: agora, o consumidor também contribui, de modo expressivo, na produção 
do produto de deseja consumir. A blogosfera possibilita tal circunstância, cujo desfecho agencia/negocia "novos/outros" valores, para além do convencional. Aqui, isso possibilita o compartilhamento de experimentaçôes que moldam as características do produto, marca e/ou serviço oferecidos. Produzido de forma colaborativa, esse livro de Wardrip-Fruin (2009) compreende a participação coletiva do usuário-interator em seu blog.

De acordo com Primo (2008, p. 123):

OCada vez mais as empresas reconhecem a necessidade de administrar a imagem que têm diante de seus diversos públicos. Os blogs oferecem uma interface para o contato direto com funcionários, fornecedores, consumidores, acionistas, etc, (sic) além de servirem como importante fonte de informação para a imprensa.

Com isso, esquenta-se o mercado a fim de atingir o consumidor exigente e astuto. Ironicamente, uma justificativa: as empresas precisam movimentar o mercado e, por isso, procuram instaurar mecanismos de competição para superar a concorrência. Disputar o consumo por meio do mercado-mídia seria tentar prever as artimanhas do concorrer. Há uma vibrante competitividade na sociedade capitalista.

Nesse caso, a noção de blogosfera no mercado-mídia auxilia na (re) leitura da experiência contemporânea. O que circula como agenciamento/negociação da informação produz permuta, troca, diferença, entre outros. Da atmosfera sensível do pensamento à aplicação acelerada da lógica computacional, divergências e desafios enfatizam o potencial comunicacional da blogosfera para o consumo tecnológico. Náo obstante, a produção de conhecimento no campo contemporâneo da Comunicação, principalmente no Brasil, constitui uma necessidade de investigar as tecnologias emergentes, que surgem na sociedade.

\section{Conclusões finais}

Como parte de uma pesquisa maior, este exercício crítico pondera um questionamento reflexivo capaz de acenar a diversidade intelectual, de pontos de vistas diferentes, entre comunicação, consumo e tecnologia. Portanto, a ideia foi arquitetar uma produção de conhecimento cujas anotaçóes, por ora relatadas, possam provocar, estimular e/ou incentivar "novas/outras" abordagens do discurso científico.

A discussão crítica aqui estabelecida incorpora diretrizes e derivativas de consumo e interação tecnológica no blog, que acionam aspectos intersubjetivos do campo contemporâneo da Comunicação. Trata-se de considerar a dinâmica flexível e deslocável da cultura digital, em especial a blogosfera que serve estrategicamente para estudar a expansão e adesão do mercado-mídia com o consumo.

A articulação entre os três tópicos enumerados ao longo do texto 
- da linguagem, da blogosfera e do exemplo - aglutina um conjunto relacional de ideias, possibilidades e desafios que inscrevem o impacto de configuraçôes tecnológicas sobre experiências e práticas contemporâneas. Dessa maneira, o blog <http://grandtextauto.org> é apenas uma exemplificaçáo de outras tantas possibilidades para se investigar experiências no universo on-line.

Talvez, para alguns críticos seria impossível sustentar a blogosfera atual como tecnologia emergente. No entanto, cabe destacar a dinâmica recorrente que aponta para a blogosfera como ambiente complexo e dinâmico, que se solidifica consequentemente como instrumento viável e facilitador de expressóes discursivas na internet.

Como resultado, este debate enfatiza temas teóricos, socioculturais e políticos da sociedade contemporânea, em busca de atualização e/ou inovação de tensôes sociais, fenômenos e valores humanos. Em síntese, as anotaçóes apontadas neste artigo indicam um leque de estratégias desenvolvidas sobre a blogosfera em consonância com o mercado-mídia, tendo em vista diferentes instâncias que se convergem na Comunicação atual. De fato, são instâncias delicadas da atual vida humana. Verificase a blogosfera em uma extensão flexível, deslocada e, cada vez mais, intersubjetiva! 


\section{Referências Bibliográficas}

BHABHA, H. K. O local da cultura. Belo Horizonte: Editora UFMG, 1998.

CANCLINI, N. G. Leitores, espectadores e internautas. São Paulo: Iluminuras, 2008.

CASTELLS, M. A sociedade em rede: a era da informação: economia, sociedade e cultura. São Paulo: Paz e Terra, 2000.

CONSONI, G. B. Conversação on-line nos comentários de blog: organização e controle das conversas nas interaçóes dialógicas no blog Melhores do Mundo. In PRIMO, Alex (Org.). Interaçôes em rede. Porto Alegre: Sulina, 2013.

CURTAIN, T. Promiscuous fictions. Into the blogosphere: rhetoric, community, and culture of weblogs. jun. 2004. Disponível em: <http://blog. lib.umn.edu/blogosphere/promiscuous_fictions.html>. Acesso em: 5 nov. 2014.

DELEUZE, G.; GUATTARI, F. Mil platôs: capitalismo e esquizofrenia. v. 5. São Paulo: Ed. 34,1997.

EAGLETON, T. Depois da teoria: um olhar sobre os estudos culturais e o pós-modernismo. Rio de Janeiro: Civilização Brasileira, 2005.

FERRARI, P. A força da mídia social: interface e linguagem jornalística no ambiente digital. São Paulo: Factash, 2010.

GUMBRECHT, H. U. Produção de presença. Rio de Janeiro: Contracampo, 2010.

HALL, S. A identidade cultural na pós-modernidade. 10. ed. Rio de Janeiro: DP\&A, 2005.

KEEN, A. Vertigem digital: por que as redes sociais estão nos dividindo, diminuindo e desorientando. São Paulo: Zahar, 2012.

LASTA, E.; BARICHELLO, E. M. da R. Proposta de uma matriz de análise de estratégias sociotécnicas de visibilidade e legitimidade presentes em blogs corporativos. Intercom: Rev. Brasil.. de Ciên. da Com.. São Paulo, v.36, n. 1, p. 249-268, jun. 2013.

LEMOS, A. A comunicação das coisas. São Paulo: Annablume, 2013.

MACIEL, S.; GONZALES, L. dos S.; REBECHI JR., A. (Orgs.). A linguagem nas midias na era das convergências. São Paulo: Cultura Acadêmica, 2014.

MANOVICH, L. Blog-based peer review. Software Studies Iniciative, New York, 22 Jan. 2008. Disponível em: <http://lab.softwarestudies. com/2008/01/blog-comments-and-peer-review-go-head.html>. Acesso em: 10 nov. 2013.

PAIS, C. T. Conditions sémantico-syntaxiques et sémiotiques de la productivité systémique, lexicale et discursive. Thèse de Doctorat d'État ès-Lettres 
et Sciences Humaines. Paris, Université de Paris-Sorbonne/Lille, Atélier National de Reproduction des Thèses, 1993.

PRIMO, A. Os blogs não são diários pessoais online: matriz para a tipificação da blogosfera. Famecos: Rev. do PPGCOM, Porto Alegre, n. 36, p. 122-128, ago, 2008. Disponível em: <http://132.248.9.34/hevila/ RevistaFAMECOS/2008/no36/17.pdf>. Acesso em: 10 nov. 2014.

RECUERO, R. Redes sociais na internet. Porto Alegre: Sulina, 2009.

SPYER, J. (Org.). Para entender a internet: noçóes, práticas e desafios da comunicação em rede. 2009. Disponível em: <http://ebookbrowse.com/ gdoc.php?id=322865036\&url=abf0af89242eec4c5b98c571d22e5d66>. Acesso em: 15 set. 2014.

VILLAÇA, N. A periferia pop na idade mídia. São Paulo: Estação das Letras e Cores, 2011.

WARDRIP-FRUIN, N. Expressive processing: digital fictions, computer games, and software studies. Cambridge-MA: MIT Press, 2009.

\section{NOTAS}

(1) Com um olhar empírico e, ao mesmo tempo, exploratório sobre as transformaçôes contemporâneas, interessa pensar a vivacidade do desempenho humano, sobretudo na intensidade imediata do agora, que é atual: o que transversaliza, interdisciplinarmente, comunicação, cultura e tecnologia.

(2) Para além das tecnologias emergentes, um avatar deve ser visto/lido como reformulação (remodelação) representacional do corpo a transcender suas habilidades humanas. O avatar partilha da transformação do objeto em outra "coisa", cujo contexto contemporâneo da cultura digital possibilita a performatividade do sujeito. Conceitualmente, propóem-se a adequação, ajuste, metamorfose, passagem, ponte e/ ou transfiguração de expressóes dispostas por efeitos hipermidiáticos 